\title{
Using Acoustic Liner for Fan Noise Reduction in Modern Turbofan Engines
}

\author{
Mohammadreza Azimi* and Fathollah Ommi** \\ Faculty of Mechanical Engineering, Tarbiat Modares University, Tehran, Iran
}

Naghmeh Jamshidi Alashti***

Faculty of Mechanical Engineering, Babol University of Technology, Babol, Iran.

\begin{abstract}
With the increase in global air travel, aircraft noise has become a major public issue. In modern aircraft engines, only a small proportion of the air that passes through the whole engine actually goes through the core of the engine, the rest passes around it down the bypass duct. A successful method of reducing noise further, even in ultra-high bypass ratio engines, is to absorb the sound created within the engine. Acoustically absorbent material or acoustic liners have desirable acoustic attenuation properties and thus are commonly used to reduce noise in jet engines. The liners typically are placed upstream and downstream of the rotors (fans) to absorb sound before it propagates out of the inlet and exhaust ducts. Noise attenuation can be dramatically improved by increasing the area over which a noise reducing material is applied and by placing the material closer to the noise source. In this paper we will briefly discuss acoustic liner applications in modern turbofan engines.
\end{abstract}

Key words: Turbofan Engine, Turbofan Engine Noise, High Bypass Turbofan Engine, Fan Noise Reduction, Acoustic Liner.

\section{Introduction}

Global air traffic is increasing because of the time efficiency of aircrafts over long distances and because of their route flexibility $[1,2]$. The well-known health effects associated with elevated sound levels produced by a commercial aircraft can include stress, annoyance, sleep deprivation and hypertension [3]. In an effort to protect people from exposure to adverse levels of noise, governments all over the world have introduced various forms of regulation to combat the problem.

Major sources of noise radiated from an aircraft fall into these categories [4]:

- Propeller noise: propellers and propfans propulsion systems

- Rotor noise: rotorcrafts such as tilt-rotor aircrafts and helicopters
- Turbomachinary noise: compressors and turbines

- Jet noise: supersonic and subsonic jets

- Airframe-generated noise: high-lift systems and landing gears

- Sonic boom: shocks from supersonic bodies

The first generation of subsonic jetliners was very noisy because of the high exhaust velocity of their engines. Introducing the high bypass ratio turbofan reduced the noise level remarkably, by 20-30 dB [5].

The associated gains in propulsive efficiency led to much lower fuel consumption, making the high-bypass turbofan the only choice for commercial aircrafts developed in the 1980s and afterwards. [this sentence was mentioned previously]. In recent decades, aircraft noise mitigation has been investigated by many researchers [6-8]. The sound that propagates in an aircraft turbofan inlet duct is almost entirely due to the fan. Fan tone noise is highly dependent on the
This is an Open Access article distributed under the terms of the Creative Commons Attribution Non-Commercial License (http://creativecommons.org/licenses/by$\mathrm{nc} / 3.0 /$ ) which permits unrestricted non-commercial use, distribution, and reproduction in any medium, provided the original work is properly cited. (c) * Corresponding Author: m_r_azimi1991@yahoo.com
** Professor
*** Ph. D 
engine power, or fan speed. Generation of fan noise depends on many factors. The dominant source of fan tone noise is usually the rotor/stator interaction while that of broadband noise is e turbulence $[9,10]$.

Various technologies have been developed to reduce the generation and propagation of turbofan noise [11]. Example of these technologies include scarf inlets, active noise control, forward swept fans, swept and leaned stators, fan trailing edge blowing, and acoustic treatment placed over the fan.

In this paper, we use a bibliographical approach to discusst the effect of an acoustic liner on fan noise reduction in ultra high turbofan engines.

\section{Fan Noise}

Turbofan engines are currently the most feasible propulsion method for commercial aircrafts because of their high power and low fuel consumption. However, with the vast array of noise regulations imposed upon aircrafts, manufacturers must now consider exterior flight noise a major design consideration. The sound that propagates in an aircraft turbofan inlet duct is almost entirely due to the fan. Fan tone noise is highly dependent on the engine power, or fan speed. Generation of fan noise depends on many factors [12]. The dominant source of fan tone noise is usually the rotor/stator interaction while that of broadband noise is turbulence [13]. The passage of air over an aircraft structure causes fluctuating pressure disturbances that propagate to an observer and are perceived as noise. These pressure disturbances are created by airflow discontinuities in the engines, where power generation demands significant changes in pressure and temperature, and on the airframe: high-lift devices and landing gears, as well as the significant wetted area associated with commercial aircrafts, create considerable turbulence [14]. The trend in aircraft engine noise has been the growing dominance of turbofan noise in the radiated acoustic field. Particularly, during a high thrust operation, such as take off, reported sound levels radiated by turbofans is typically $15-20 \mathrm{~dB}$ greater than the levels of broadband noise [15]. Furthermore, with higher bypass ratio engines becoming the norm, the noise levels can only be expected to rise. Various methods have been developed to reduce the generation and propagation of turbofan noise.

\section{Acoustic liner}

A successful method of further reducing noise , even in ultra-high bypass ratio engines, is to absorb the sound created within the engine. Acoustically absorbent material or acoustic liners can be placed on the interior surfaces of the engines. Probably the most common passive method of noise control is the use of acoustic liners. The liners absorb the radiated acoustic energy, thereby reducing the far-field noise levels.

Liners are usually placed at the inlet and/or outlet of the engine. A single layer acoustic liner, composed of a perforated sheet with a honeycomb core, is shown in Figure.1, with labels on the most crucial elements. This arrangement produces an array of single degree of freedom resonators. The basic mechanism that allows an acoustic liner to reduce outwardly propagating sound from a turbofan engine parallels the workings of a Helmholtz resonator. Some liners have used multiple layers of honeycomb and perforated sheets to produce multiple degree of freedom resonators, with more than one neck and volume cavity [16-18].

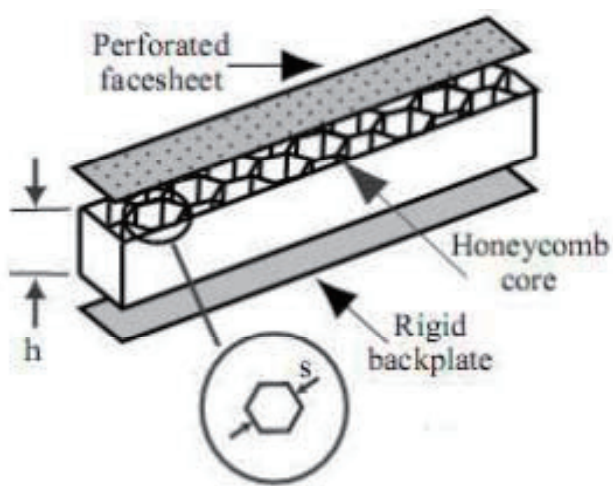

Fig. 1. Schematic of Acoustic Liner[ 19]

The acoustic liner may cover most of the available surface, both in the inlet and exhaust ducts, based on an optimization procedure involving antagonist factors like the installation of anti-icing systems. Liners are usually manufactured in sections, each of which covers a part of the duct's circumference. This facilitates the manufacture and installation of the lining inside the nacelle [20]. The sections are joined together by longitudinal strips or splices. The splices will be acoustically hard, meaning that there will be discontinuities in the acoustic impedance around the circumference of the duct. The typical types of acoustic liners are locally reacting cavity linings. The specific acoustic impedance of these types of liners depends on the properties of the lining, the mean flow and the frequency of the sound [21]. In general, it is more difficult to attenuate the fan tones as the engine power is increased, especially at high supersonic fan speeds. However, the liners increase the engine weight, which is undesirable. Also in the future, the bypass ratio will 
be increased, and the inlet length will not be scaled with the diameter. These changes will make liners less effective. Their performance is always limited by their confined length, especially for aero engines, which are considerable in number in size and where their multiple dominant tones are related to buzz-saw noise or rotor-stator interaction noise.

Different methods of optimization can focus on the variations in the treatment depth, core-cell dimensions, and number of layers in the lining. Once passive optimization method reached its limit, active methods were studied and developed to further improve upon the success of the passive liner. An active method in this context refers to a method which requires the addition of energy into a system. Dividing the acoustic liner into segments is a method that has been found improved the attenuation of ability of the liner, and an excellent review of the major works that contributed to this knowledge was authored by W. R. Watson [19].

The concept of non-uniform liners has been studied by several authors: Lasing and Zarumski [23] appear to be the first to have published work on the axially segmented liner, using modematching techniques. This type of the axially segmented liner is of interest because it can be used to increase the attenuation of fan tones at high supersonic fan speeds. Unruh [24] first examined how the liner's length, as well as its impedance, may be tuned to optimize the attenuation. Also, both Baumeister [25] and Tsai [26] realized that the first segment of the lining acts as a scatterer, which facilitates the attenuation of the sound in the adjacent lined segments. However, Baumeister concluded that an optimized axially segmented liner fails to offer sufficient advantage over a uniform liner to warrant its use except in low-frequency, single-mode applications.

In a circular-section lined duct, with circumferentially varying wall impedance, it is not possible to separate $r$ and $y$, in order to find the analytic expressions for the modes of the duct. Watson [27], and also Fuller [28, 29], proposed an analytic solution to this type of problem. The wave equation was solved by separating the $\mathrm{x}$-dependence, and then expressing both the mode shapes and wall impedance as Fourier series expansions in y. Then, a solution can be found, in principle, by solving a system of eigen equations.

The fan tones are harmonics of the blade passing frequency (BPF), which is generated by rotor-stator interactions and other similar mechanisms such as interaction of what with mean flow distortion and scattering by liner discontinuities. In aero-engines operating with supersonic fan tip speeds, for example at the engine "cutback" and "sideline" operating conditions (nominally about 80-85 and 90-95\% fan speed, respectively), an acoustic signature containing energy spread over a range of harmonics of the engine shaft rotation frequency will be generated. The name "buzz-saw" noise or multiple pure tones is generally used to describe this component of fan noise. The pressure signature attached to a supersonic ducted fan will be a sawtooth waveform. The nonlinear propagation of a high-amplitude irregular sawtooth waveform upstream inside the inlet duct redistributes the energy amongst the buzz-saw tones [30]. "Buzz-saw" noise is radiated from a turbofan inlet duct when the fan tip speed is supersonic. McAlpine et al [30] showed that the principal source of buzz-saw noise is not always the rotoralone pressure field. Non rotor-alone scattered tones can be a significant source of buzz-saw noise at low supersonic fan speeds. "Buzz-saw" noise is the principal tone noise source radiated from a turbofan inlet duct at supersonic fan speeds. The noise source consists of a set of tones, known as engine orders (EO), that are harmonics of the engine's shaft rotation frequency. These EO tones are the buzz-saw noise. The levels of the scattered modes can be significantly reduced by the buzz saw noise. The level of the scattered modes can be significantly by having thinner splices.

In another study by Mcalpine, et al [31], the effect of an acoustic liner on buzz-saw noise was examined. However, at the sideline, the rotor-alone field is well cut-on. At this fan speed, the rotor - alone modes are predicted to remain the principal source of fan tones noise. The levels? of the scattered modes at the sideline can be reduced with thinner splices. However, at high fan speeds, thinner splices are not expected to increase the overall sound power transmission loss.

This is because the rotor-alone pressure field is well cuton, and poorly absorbed by the duct liner. Acoustic liners in current aircraft engines are generally located in the inlet and/or the aft fan duct. If the liner is placed nearer to the fan rotor, or over the rotor, preliminary tests [32] suggested that significant additional noise attenuation could be realized. Sutliff and et.all [33] used a Foam- Metal Liner (FML) installed in close proximity to the fan. In their study, two FML designs were tested and compared to the hardwall baseline. Traditional single degree-of-freedom liner designs were also evaluated to provide a comparison. They showed that the FML designs achieved up to $5 \mathrm{~dB}$ Acoustic Power Level (PWL) overall attenuation in the forward quadrant, equivalent to the traditional liner design.

\section{Conclusions}

The rotating fan within a turbofan engine is a significant source of broadband noise, which spans a large range of the audible frequency spectrum. Although engineers have some degree of control over the noise produced at the exhaust and 
over the broadband noise produced by the fans, they have less control over the noise produced at the inlet duct, which is also a critical issue. Acoustic liners are an excellent means to reduce noise propagation from a turbofan engine.

\section{References}

[1] Mofid Gorji-Bandpy, and Mohammadreza Azimi, "Technologies for jet noise reduction in turbofan engines", Aviation, Vol. 16, Isuue 1, 2012, pp. 25-32.

[2] Mohammadreza Azimi and Fathollah Ommi, "Using Microjets as an Efficient Technique for Jet Noise Reductionin High-Bypass Turbofan Engines", Journal of Mechanical Engineering and Technology, Vol. 2, No. 1, pp. 49-53.

[3] K. D. Kryter. The handbook of hearing and the effects of noise: physiology, psychology, and public health. Emerald Group Publishing Limited; first edition, 1994.

[4] D. G. Crighton, "Airframe Noise", Aeroacoustics of Flight Vehicles: Theory and Practice, NASA RP-1258, edited by H. H. Hubbard, Vol. 1, 1991, pp. 391-447.

[5] Smith, M. J. T., "Aircraft Noise", 1st ed., Cambridge University Press, Cambridge, England, UK, 1989, pp. 120134.

[6] Narkiewicz, J. and Pietrucha, J., "Reduction of helicopter vibration and noise level by active control technology", Aviation. Scientific Works, Vol. 3, 1998, pp. 83-85.

[7] Žilienè, D. and Stankūnas, J., "Analysis of influence of aircraft noise limitations following requirements of European Union on sector of Lithuania air transport services", Aviation, Vol. 6, issue. 1, pp. 34-40

[8] Vanker, S., Enneveer, M. and Rammul, I., "Noise assessment and mitigation schemes for Estonian airports",Aviation, Vol. 13, No.1, 2009, pp. 17-25

[9] Trefney, C.J. and Wasserbauer, J.W., "Lowspeed Performance of an Axisymmetric, MixedCompression,Supersonic Inlet With Auxiliary Inlets", NASA TP-2557, 1986.

[10] Tyler, J. M., and sofrin, T.G., Axial Compressor Noise Studies, SAE Transactions, Vol.70, 1962.

[11] Morin, B. L., "Broadband Fan Noise Prediction System for Turbofan Engines”, NASA/CR-2010- 216898, Vol. 1, 2010.

[12] Hanson, D.B., "Theory for Broadband Noise of Rotor and Stator Cascades With Inhomogeneous Inflow Turbulence Including Effects of Lean and Sweep", NASA/CR2001-210762, May 2001.

[13] Astley, R. J., Sugimoto, R. and Mustafi, P., "Computational aero-acoustics for fan duct propagation and radiation. Current status and application to turbofan liner optimization", Journal of Sound and Vibration, Vol. 330, pp.
3832-3845.

[14] Huff, D. L., "Noise Reduction Technologies for Turbofan Engines", NASA/TM-2007-214495, 2007.

[15] Mofid Gorji-Bandpy, and Mohammadreza Azimi, "Airframe Noise Sources and Reduction Technologies in Aircraft", Noise and Vibration Worldwide, Vol. 43, No. 9, 2012, pp. 29-36.

[16] Rayleigh, L., "The Theory of the Helmholtz Resonator", In Proceedings of the Royal Society of London, Vol. 92, No. 638, 1916.

[17] Helmholtz, H.v., On the Sensations of Tone. 1954, New York: Dover.

[18] Dean, P.D., "On the "In-Situ" Control of Acoustic Liner Attenuation”,. Journal of Engineering for Power, Vol. 99, No. 1, 1976, pp. 63-70.

[19] M. G. Jones, T.L.P. and W. R. Watson, Comparison of Acoustic Impedance Eduction Techniques for LocallyReacting Liners, In 9th AIAA/CEAS Aeroacoustic Conference and Exhibit, Hilton Head, SC, 2003, pp. 11.

[20] Jeff D. Eldredge, and A.P.D., "The Absorption of Axial Acoustic Waves by a Perforated Liner with Bias Flow", Journal of Fluid Mechanics, Vol. 485, 2003, pp. 307-335.

[21] Mcalpine, A. and Wrigh, M.C.M., "Acoustic scattering by a spliced turbofan inlet duct liner at supersonic fan speeds", Journal of Sound and Vibration, Vol. 292, pp. 911934.

[22] Watson, W.R., Circumferentially Segmented Duct Liners Optimized for Axisymmetric and Standing-Wave Sources, NASA, Editor. 1982: Hampton, Virginia. pp. 51.

[23] Lansingm D.L. and Zorumski, W.E., "Effects of wall admittance changes on duct transmission and radiation of sound", Journal of Sound and Vibration, Vol. 27, 1973, pp. 85100.

[24] Unruh, J.F., "Finite Length tunning for low-frequency lining design, Journal of Sound and Vibration", Vol. 45, No. 1, 1976, pp. 5-14.

[25] Baumeister, K.J., "Evaluation of optimized multi sectioned acoustic liners", AIAA Journal, Vol. 17, No. 11, 1979, pp. 1185-1192.

[26] Tsai, M.S., "Mode scatterer design for fan noise suppression in two-dimensional ducts", Journal of Sound and Vibration, Vol. 83, No. 4, 1982, pp. 501-512.

[27] Watson, W., "Noise suppression characteristics of peripherally segmented duct liners”, NASA TP-1904, 1981.

[28] Fuller, C.R., "Propagation and radiation of sound from flanged circular ducts with circumferentially varying wall admittances, I: semi infinite ducts", Journal of Sound and Vibration, Vol. 93, No. 3, 1984, pp. 321-340.

[29] Fuller, C.R., "Propagation and radiation of sound from flanged circular ducts with circumferentially varying wall 
admittances, II: finite ducts", Journal of Sound and Vibration, Vol. 93, No. 3, 1984, pp. 341-351.

[30]Mcalpine, A. and Fisher, M. J., "On the prediction of "buzz-saw" noise in acoustically lined aero-engine inlet ducts", Journal of Sound and Vibration, Vol. 265, No. 1, 2002, pp. 175-200.

[31]Mcalpine, A., Fisher, M. J. and Tester, B. J., "Buzzsaw" noise: A comparison of modal measurements with an improved prediction method", Journal of Sound and Vibration, Vol. 306, 2007, pp. 419-436.

[32] Sutliff, D.L. and Jones, M.G., "Foam-Metal Liner Attenuation of Low-Speed Fan Noise", AIAA, pp. 2008-2897.

[33] Sutliff, D. L., Elliott, D. M.; Jones, M. G. and Hartley T. C., "Attenuation of FJ44 Turbofan Engine Noise With a FoamMetal Liner Installed Over-the-Rotor", NASA Glenn Research Center, Cleveland, OH, NASA/TM-2009- 215666, 2009. 